\title{
Pancreatic Adenocarcinoma
}

National Cancer Institute

\section{Source}

National Cancer Institute. Pancreatic Adenocarcinoma. NCI Thesaurus. Code C8294.

An adenocarcinoma which arises from the exocrine pancreas. Ductal adenocarcinoma and its variants are the most common types of pancreatic adenocarcinoma. 